\title{
Ueber Meningokokkentypen.
}

Von Dr. Karl Hundeshagen in Freiburg i. Br., früher in StraBburg i. E.

Die in Nr. 2 dieser Wochenschrift veröffentlichten, sehr interessanten Ausführungen von $F$. $N$ e u f e ld ,Neue Forschungsergebnisse über Pneumonie" "eben mir die Anregung, dem von $\mathrm{N}$ u feld beschriebenen Verhalten der Pneumokokken das durchaus ähnliche der Meningokokken zur Seite zu stellen und auf die praktische Wichtigkeit dieser Frage hinzuweisen. Ne uf eld hat in Gemeinschaft mit $\mathrm{Händel}$ bereits vor über 10 Jahren festgestellt, $\mathrm{da} \beta$ es verschiedene Typen der Pneumokokken gibt, die sich serologisch völlig verschieden verhalten und dementsprechend auch therapeutisch nur durch ihr homologes Antiserum beeinflußt werden können. In seiner oben genannten Veröffentlichung berichtet er nun über die weiteren Forschungen nach dieser Richtung, welche in eingehendster Weise im Rockefeller-Institut in den Jahren 1912 bis 1920 durchgeführt worden sind und die zu dem Ergebnis geführt haben, da 3 es 4 Typen von Pneumokokken gibt, welche sich nur serologisch unterscheiden lassen.

Ganz. entsprechend liegen nun offenbar die Verhältnisse bei den Meningokokken: Gesetzt den Fall, daB auch bei ihnen verschiedene Typen im obigen Sinne zu unterscheiden sind und dem Unter sucher nicht gerade immer nur ein und derselbe Typ, sondern verschiedene Typen unter die Hände kommen, dann ist es klar, daf die serologische Prüfung mit einem bestimmten Antiserum auch nur bei einem Teil der Fälle befriedigen kann, in vielen Fällen aber im Stiche lassen muß. Und in der Tat wird jeder, der zahlreiche Meningokokkenstämme zu prüfen gehabt hat, oft genug von der serologischen Untersuchung im Stiche gelassen worden sein. In diesem Sinne haben sich auch die verschiedensten Forscher geäuBert, sodaß Kutscher in seiner Abhandlung üher Meningokokken im Lehrbuch von Kolle - W a s s e r m a n n den Wert der serologischen Prüfung dahin einschränken muB, daB Vorsicht im Urteil auf Grund der Agglutination geboten ist, da "schweragglutinable bzw. inag. glutinable Stämme vorkommen". Er verweist dabei auch auf die Feststellung von $\mathrm{Eb} \mathrm{rll}^{2}$ ), daB ,derselbe Meningokokkenstamm durch verschiedene mit echten Meningokokken hergestellte Sera sehr ungleich hoch agglutiniert werden kann". Auf Grund seiner Untersuchungen an 18 aus Lumbalpunktaten gezüchteten Meningokokken stämmen spricht $\mathrm{Eb}$ erle die Ueberzeugung aus. daß die Agglutination weder für die Diagnose der Meningokokkeninfektion noch für die Differenzierung ähnlicher Mikroorganismen als ausschlaggebend betrachtet werden kann. Die unbefriedigenden Ergebnisse der agglutinatorischen Prüfung äußern sich auch darin, daB man die Beobachtung für Meningokokken auf 24-48 Stunden ausgedehnt

1) In einem Falle von weiblicher' Gonorrhoe 'wurde 3 der IKapselinhalt einfach in die Scheide ausgedrïrkt und einige Tropfen nachher in die Harnöhre gehracht un die Scheide tamponiert. Die Patientin führte die Manipulation selhst zweimal tägliri vor dem Spiegel aus und erschien nach drei Tagen frei von AusfluB, der anfänglich stark und dickeitrig war und Gonnkokken enthielt. - Neuerdings begnligte irh mich ber der mannilichen Gonorrhoe mit der Anwendung von nur $1 / 2$ Kapsel, also vor $21 / 2 \mathrm{~g}$ Irftationen der gesunden Urethralpartien aus 
hat und in der Einführung des Verfahrens von Kutscher, die Agglutination bei $55^{\circ}$ vorzunehmen. Aber selbst bei Anwendung dieses Verfahrens zeigt es sich, wie $K u$ tscher selbst betont, ,daB es ohne Zweifel echte Meningokokken gibt, welche auch bei $55^{\circ}$ gar nicht oder nur sehr schwach agglutiniert werden".

Ich selbst hatte nun während des Krieges am Bakteriologischen Institut in Straßburg außerordentlich zahlreiche Meningokokkenstämme zu prüfen (vgl. meinen Aufsatz in der M. m. W. $1922 \mathrm{Nr} .17$ ). Soweit die serologische Prüfung in Betracht kam, waren die Ergebnisse so unbefriedigend, daß ich später in den meisten Fällen darauf verzichtete, um so mehr, als das Material nicht $\mathrm{zu}$ bewältigen war. Es wurde öfters beobachtet, daß zweifellose Meningokokkenstämme aus dem Lumbalpunktat Meningitiskranker nicht agglutiniert wurden, während andere Stämme aus Rachenabstrichen deutliche Agglutination zeigten. Zudem ließ sich häufig Agglutination mit Normalpferdeserum feststellen. Benutzt wurden möglichst hochwertige agglutinierende Sera vom Institut für Infektionskrankheiten in Berlin und - soviel mir erinnerlich - aus dem Kaiserlichen Gesundheitsamt. Da mich die Agglutination nicht befriedigte, stellte ich mir dann selbst durch Immunisierung eines Kaninchens ein Antiserum her, welches aber die Berliner Sera höchstens um ein weniges übertraf. Etwas verbessern ließ sich die Agglutination durch Anwendung erhöhter Temperatur nach Kutscher. Jedoch unbefriedigend blieb die Reaktion auch dann noch.

Um so auffälliger und im höchsten Grade überraschend mußten die während der letzten Zeit meiner Tätigkeit in Straßburg beobach teten Agglutinationen für mich sein. Schon während des Krieges waren hie und da kurze referierende Bemerkungen durchgesickert, aus denen hervorging, daB die Bakteriologen im Ausland mehrere Typen der Meningokokken unterschieden. Auf Grund dieser Anschauungen war man im feindlichen Ausland auch bereits dazu geschritten, Antisera gegen die verschiedenen Typen für diagnostische und therapeutische Zwecke herzustellen. Da ich nun in Straßburg auch nach Beginn der Franzosenzeit noch einige Monate meine Stelle am Bakteriologischen Institut innehatte, so bot sich mir Gelegenheit, in einer kleinen Reihe von Meningitisfällen die serologische Prüfung der gezüchteten Meningokokkenstämme mit Pariser Seren vorzunehmen.

Ueber die Vorgeschichte dieser Seren berichten M. Nicolle, E. Deb a in und C. Jou a n in ihrem Aufsatz: „Sur les Meningocoques et les sérums antimeningocoques", indem sie zunächst gleichfalls auf die oben erörterte Tatsache hinweisen, daß sich morphologisch und kulturell übereinstimmende Meningokokkenstämme Antiseren gegenüber durchaus verschieden verhalten können, was bereits von Elser, Huntoon, Dopter, Arkwright, Gordon und Ellis festgestellt sei. Auf Grund dieser Feststellungen wurde eine Anzahl monovalenter Antisera durch Immunisierung von Pferden gewonnen. Mit diesen wurden 105 Meningokokkenstämme der verschiedensten Herkunft geprüft. Dabei ergab sich, die Unterscheidbarkeit. von 4 verschiedenen Typen. Wenn man die in ihrer Wirksamkeit verschiedenen Antisera mit Typus A, B, C und D bezeichnet, so zeigen manche Stämme nur mit Serum $A$, andere nur mit Serum. B, wieder andere nur mit Serum $C$ und so weiter deutliche Agglutination. Um also zu entscheiden, welcher Meningokokkentypus im einzelnen Krankheitsfall vorliegt, muß man die gewonnene Kultur mit allen 4 Serumarten prüfen. Es müssen daher 5 Reihen Gläschen angesetzt werden, die 5. als Kontrollreihe mit Normalserum. Jede Reihe enthält 4 Gläschen mit je $1 \mathrm{ccm}$ Meningokokkenaufschwemmung und fallenden Serummengen: 1/20,1/50,1/100 und $1 / 20 \mathrm{ccm}$ Serum. Die Gläschen kommen nicht in den Brutschrank oder das Wasserbad, sondern werden sofort in den Gestellen 5-10 Minuten kräftig geschüttelt. Dabei stellt sich in ganz überraschender Weise bereits in den ersten Minuten eine mit bloßem Auge deutlich sichtbare Agglutination in Glas 1 von einem der 5 Gestelle ein, während alle übrigen Gläschen nnverändert sind, soda $\beta$ damit schon entschieden ist, zu welchem Typus der betreffende Meringokokkenstamm gehört. Nach etwa 5-10 Minuten pflegt dann auch in Glas 2 des betreffenden Gestelles die Agglutination deutlich zu werden. In Glas 3 und 4 mit den höheren Verdünnungen wird sie erst bedeutend später sichtbar, weshalb das Endergebnis der Agglutination (Grad der Agglutinabilität) erst am folgenden Tage abgelesen wird, nachdem die Gläschen bis dahin bei Zimmertemperatur gestanden haben. In den von mir beobachteten Fällen trat stets bis zur Verdünnung 1:200 deutliche Agglutination ein bei völlig einwandfreien Kontrollen.

Aus dem geschilderten Ablauf der Reaktion ist ersichtlich, welch ungeheurer Abstand besteht zwischen den früheren unbefriedigenden Ergebnissen der Agglutination und den serologischen Prüfungen, die mit den geeigneten Serumtypen vorgenommen werden. Im ersten Falle häufig ein negatives oder unklares Ergebnis nach mindestens 24stündiger Beobachtung bei Brutschranktemperatur oder bei $55^{\circ}$, im letzteren Falle klare Entscheidung schon nach wenigen Minuten in Glas 1 , welches man zunächst allein zu beobachten braucht. Ich pflegte mit den zwischen beiden Händen gehaltenen 5 Gestellen, sie lebhaft schüttelnd, einen kleinen Rundgang in dem Arbeitsraum zu machen und hatte stets nach einigen Minuten bereits klare Entscheidung: ausgezeichnete Agglutination mit einem der vier Serum- typen, mit allen anderen negatives Ergebnis. Uebrigens geben Nicolle, Debain und Jouan in ihrer oben genannten Arbeit an, nur selten beobachtet wird, sodaß im allgemeinen die Prüfung mit Serumtyp A und B genüge. Auch in den von mir beobachteten Fällen handelte es sich um Typ B und einmal um Typ A.

Für die Praxis ist die Gewinnung solcher Serumtypen von besonderer Wichtigkeit, denn ebenso wie ein gegebenes Meningokokkenserum gegen irgendeinen Meningokokkenstamm agglutinatorisch versagt, so lä̉t es auch therapeutisch gegen diesen Stamm völlig im Stiche. Serumtyp B ist nur therapeutisch wirksam gegen einen Krankheitserreger vom Typus B, nicht aber gegen A und C. Die Verhältnisse liegen also hier genau so wie sie Ne ufeld (siehe oben) für die Preumokokken klargestellt hat. Von großer praktischer Bedeutung ist natürlich auch, daß sich die Entscheidung, welcher Erregertyp im einzelnen Falle yorliegt, so rasch, wie oben geschildert treffen läßt, damit sofort die richtige Serumtherapie eingeleitet werden kann. Da es sich übrigens fast stets um den Typ $\mathrm{B}$ oder $\mathrm{A}$ handelt, so geben die obengenannten Forscher den Rat, wenn aus irgendeinem Grunde die serologische Entscheidung noch nicht möglich war, als Heilserum zunächst eine Mischung von Typus $A$ und $B$ anzuwenden.

Nach dem Gesagten scheint es mir notwendig zu sein, daß sich unsere großen Serumwerke dieser Fragen, welche außer in der oben angeführten Arbeit unter anderen auch in den Annales de L'Institut Pasteur erörtert sind, annehmen, um die verschiedenen Serumtypen zu gewinnen und sie in die Praxis einzuführen. Gegenüber der Wirkungsbreite eines beispielsweise sehr hochwertigen Typhusantiserums beruht offenbar die ausgesprochen univalente Wirkung der Meningokokkensera auf nur bestimmte Stämme auf der Niedrigkeit des Titers, der sich bei Meningokokken überhaupt nur erreichen läßt. Wenn man früher manche Kokkenstämme, obwoh sie morphologisch und kulturell vollkommen dem Bilde der Meningokokken entsprechen, allein auf Grund negativer Agglutination mit einem beliebigen Meningokokkenantiserum als Pseudomeningok okke $n$ bezeichnet hat, so ist dieser Bewertung der betreffenden Stämme wohl auch der Boden entzogen, sobald man verschiedene Meningokokkentypen annimmt, denn in den fraglichen Fällen wurde ja nicht mit den verschiedenen Serumtypen geprüft.

An dieser Stelle muB noch besonders auf die von Hirsch. bruch ${ }^{1)}$ beschriebenen Meningokokkenstämme hingewiesen werden. Auf Grund seiner genauen serologischen Untersuchungen ist $\mathrm{Hirsch}$. bruch auch bereits zu dem SchluB gekommen, daB zwei voneinander verschiedene Arten Meningokokken anzunehmen sind. Die von ihm festgestellte Art, die sich serologisch von den gewöhnlichen Weichselbaumschen Meningokokkenstämmen scharf trennen lie $B$, bezeichnet er als A-Meningokokken; zugleich hebt er hervor, daB eine Heilwirkung im Körper gegen diese A-Meningokokken nur von einem spezifischen, zu ihnen passenden Antiserum ausgseübt werden kann. Seine. Feststellungen stimmen also durchaus zu dem oben Ausgeführten und $\mathrm{zu}$ den Ergebnissen der eingangs erwähnten Preumokokkenforschungen.

Vielleicht sind gewisse Unterschiede im kulturellen oder biologischen Verhalten der Meningokokkenstämme, die nicht selten zu beobachten sind, zum Teil auch der Ausdruck für die Zugehörig. keit $\mathrm{zu}$ verschiedenen Typen: so die ziemlich häufig zu beobachtenden Verschiedenheiten im Zuckerzerlegungsvermögen oder die besonders schwere Züchtbarkeit und das ungeheuer rasche $\mathrm{Ab}$ sterben einzelner Stämme, welch letztere Eigenschaft auch $\mathrm{Hirsch}$. bruch bei seinen A-Meningokokken aufgefallen ist.

Inwieweit die oben beschriebene Technik des Schüttelns allein einen die Agglutination befördernden Einfluß ausübt, müBte natürich auch noch genauer festgestellt werden. Ich habe seit Verlassen des Elsasses keine Gelegenheit zu derartigen Untersuchungen mehr und beabsichtige im wesentlichen durch diese Arbeit Anregungen zu geben. 